\title{
Virando a página: uma proposta para renovar o único caderno de literatura em circulação na imprensa de Imperatriz (MA)
}

\author{
Turning page: a proposal to renew the unique literature notebook \\ in circulation in the press of Imperatriz (MA)
}

\section{Volviendo a la página: una propuesta para renovar el único cuaderno de literatura en circulación en la prensa de Imperatriz (MA)}

Thaisa Bueno ${ }^{1}$, Marcelli Alves ${ }^{2}$, Diana Costa ${ }^{3}$, Reis Hyana ${ }^{4}$

\section{Resumo}

A proposta desse artigo é resgatar a história do caderno Extra, o único suplemento de literatura em circulação na mídia impressa de Imperatriz, a segunda maior cidade do Maranhão. O estudo se propõe, ainda, a partir de uma análise minuciosa da produção do que, em tese, deveria comportar um caderno literário, teorizar uma possível mudança para o suplemento e alvitrar uma modificação na publicação de acordo com o arcabouço teórico do Jornalismo Literário. Trazendo ao conhecimento o histórico dos folhetins, dos cadernos literários e chegando ao histórico do caderno de literatura da Academia Imperatrizense de Letras, o artigo mostra que, embora por muito tempo o jornalismo literário tenha ficado atrelado ao livro reportagem, esse tipo de jornalismo rompe com o modelo tradicional do lide e tem público cativo.

\begin{tabular}{|c|c|}
\hline & Acesse este artigo online \\
\hline \multirow{2}{*}{ 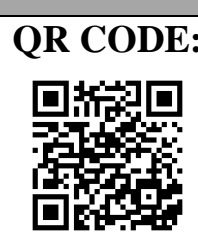 } & $\begin{array}{l}\text { Website: } \\
\text { http://www.revistas.ufg.br/index.php/ci }\end{array}$ \\
\hline & $\begin{array}{l}\text { DOI: } \\
\text { http://dx.doi.org/10.5216/ci.v20i3.43833 }\end{array}$ \\
\hline
\end{tabular}

Palavras-chave: Suplemento de literatura. Jornal O Progresso. Jornalismo literário.

\section{Abstract}

This article proposal is to rescue the history of the extra book, the only literature supplement circulating at Imperatriz print media the second biggest city from Maranhão. The study also proposes, from a thorough analysis of the production than in theory, should admit a literary book, theorize a possible change to the supplement according to the theoretical framework of the literary journalism. Bringing to know the history of the serials, from the literary notebooks reaching the history of the literature notebook of the Imperatrizense Academy of Letters the article shows that although for a long time literary journalism has been tied to the book report that type of journalism that breaks with the traditional model the lide has a captive audience.

Keywords: Literature Supplement. Journal The Progress. Literary journalism.

\footnotetext{
${ }^{1}$ Doutora em Comunicação pela PUC-RS, Mestre em Letras pela UFMS e prof. adjunta no curso de Jornalismo na UFMA de Imperatriz.E-mail: thaisabu@gmail.com

${ }^{2}$ Doutora em Comunicação pela UNB, professora assistente na UFMA em Imperatriz. E-mail: marcellialvessalva@gmail.com

${ }^{3}$ Jornalista formada pela UFMA, em Imperatriz. E-mail: linidiana_cardoso@ hotmail.com

${ }^{4}$ Jornalista formada pela UFMA, em Imperatriz, e estudante de especialização na mesma instituição. E-mail: weniahiana@hotmail.com.
}

Comun. \& Inf., Goiânia, GO, v. 20, n. 3, p. 49-63, out./dez. 2017 


\section{Resumen}

El propósito de este artículo es de rescatarla historia del cuaderno adicional, el único suplemento de la literatura que circula en los medios impresos de Imperatriz, la segunda ciudad más grande do Maranhão. Los objetivos del estudio, todavía, a partir de una critica detallado de la producción que, en teoría, debe comportar se un cuaderno literario, teorizar un posible cambio para el suplemento y opinar un cambio en la publicación de acuerdo con la estructura teórico de la literatura do Jornalismo. $\mathrm{El}$ artículo muestra que aunque por mucho tiempo el periodismo literario ha quedado atado al libro reportaje ese tipo de periodismo que rompe con el modelo tradicional del lide tiene público cautivo.

Palabras clave: Suplemento de la literatura. Prensa O Progresso. Periodismo literario.

\section{INTRODUÇÃO}

e olharmos para a história da imprensa no Brasil, vamos ver que o jornalismo
e a literatura, apesar de serem áreas distintas, viveram estreitamente
relacionados. No início do século XVII, por exemplo, a imprensa brasileira era caracterizada como "literária", principalmente devido à participação de escritores no jornal.

Durante um largo período de tempo que abrange desde o século XVIII até o $\mathrm{XX}$ as imprensas brasileiras e francesas poderiam ser caracterizadas como "literárias". Os jornais anteriormente mais políticos e polêmicos se tornaram literários e mundanos, contando com a presença de inúmeros escritores em sua página. (TRAVANCAS, 2011, p. 25-26).

Além disso, diversos fatores permitiam caracterizar o jornal impresso como "literário", tal como o fato de os "jornais publicarem com frequência em suas páginas romances e folhetins; por apresentarem um estilo de texto sem a objetividade e concisão marcantes do jornalismo no século XX, e por estimularem e divulgarem a produção literária da época" (TRAVANCAS, 2011, p. 25-26).

Porém, a partir da Segunda Guerra Mundial, a linguagem jornalística começou a trilhar um estilo próprio. Marcada pela objetividade e pelo distanciamento, essa nova forma de narrar os fatos do cotidiano fez com que o texto, que até então era o primo chegado das produções literárias, começasse a ter mais diferenças do que proximidades com os textos de escritores. "Nossos jornais, banhando-se na experiência da objetividade e dependendo diretamente do noticiário telegráfico, aprenderam um novo estilo, seco e forte, que já não tinha qualquer ponto de contato com o beletrismo". (DINES, 1986, p. 26). 
Essa mudança, é importante frisar, tem menos relação com as demarcações estéticas do que se possa pensar. Na verdade, tratava-se, substancialmente, de garantir espaço mercadológico. Conforme Lage (1999), essas reestruturações de estilo aconteceram num momento em que os jornais começaram a se transformar em empresas, fazendo com que o ideal social e a linguagem literária fossem deixados de lado. Na década de 1950, destaca o autor, os manuais de redação passaram a ser adotados e o texto uniformizado de acordo com a ideologia do veículo. Ele afirma, inclusive, que os manuais "atendiam à necessidade de generalizar procedimentos de técnica de redação que estavam sendo adaptados de modelos estrangeiros" (LAGE, 1999, p. 50). Os jornalistas, portanto, estavam presos a um padrão de escrita objetiva e informativa e, inevitavelmente, mais distante da linguagem literária do período do seu surgimento. Houve então um processo que Travancas (2011) define como "desliteraturização".

O cosmopolitismo modernizante na imprensa reduz o impacto, gerando um empobrecimento do lugar da literatura; com o avanço tecnológico (telégrafo, telefone) o jornal se tornou menos opinativo e mais informativo; o surgimento de diferentes formas artísticas, como a novela, vem ocupar o lugar das histórias de folhetim, por exemplo; e por último, mas fundamental, o fato do livro ter se transformado em mercadoria de fácil aceso ao público, fazendo com que o escritor não precise mais publicar seus textos na imprensa para ser conhecido. (TRAVANCAS, 2011, p. 43).

Paralelamente a isso tudo, a literatura passou a ter menos espaço na imprensa, ficando restrita aos cadernos literários, que surgem com a função de preservá-la. De acordo com Travancas (2011), o caderno literário é considerado um espaço cujo conteúdo mais elaborado, autoral até, está voltado para um público intelectual. Por isso, atualmente, a mídia impressa o considera um artigo de luxo. Além disso, eles estão mais raros e menores, por não serem tão rentáveis. Dos grandes jornais do Brasil, poucos mantêm espaços tradicionais para discutir literatura. Só para ter uma ideia, o jornal brasileiro de maior circulação no país, a Folha de $S$. Paulo de acordo com levantamento da Associação Nacional de Jornais (ANJ), não publica um suplemento de literatura desde que o veículo deixou de produzir o caderno Mais!, que mantinha o suplemento literário Ilustrada, em 2010. Atualmente a página Ilustrada é o caderno de Cultura do jornal, e não um suplemento voltado para a literatura como foi anteriormente. No veículo, o tema literatura disputa espaço com outros temas.

A mudança não é exclusividade do veículo paulista, a literatura, como um todo, perdeu espaço no mundo moderno. Na avaliação de Travancas (2011), isso aconteceu devido 
às mudanças sofridas pela sociedade que, na mídia, se reflete, principalmente, nos leitores, que vivem em ritmo mais acelerado e recebem grande quantidade de informações em pouco tempo. Um leitor com esse perfil mostra pouco interesse nos suplementos densos e leitura lenta como é o padrão dos cadernos nesse formato. Some-se a isso o fato de que o índice de leitura no país hoje é considerado extremamente baixo. De acordo com a pesquisa Retratos da Leitura no Brasil, realizada em 2012, 75\% dos brasileiros nunca frequentaram uma biblioteca, portanto, apenas metade da população pode ser considerada leitora.

A venda de livros no Brasil também é considerada insignificante se comparada a de outros países. Conforme levantamento realizado em 2012 pela Associação Nacional de Livrarias (ANL), no Brasil existe 3.481 livrarias, apenas mil a mais que a França que tem 65 milhões de habitantes, correspondente a pouco menos de um terço da população brasileira, que atualmente tem mais de 190 milhões habitantes. A pesquisa também revelou que 1.751 livrarias do país estão localizadas nas capitais, e que 1.829 delas estão na Região Sudeste. O Maranhão, portanto, encontra-se em uma região com poucas livrarias. Em Imperatriz, a segunda maior cidade desse Estado, conforme dados do IBGE de 2010 (último censo realizado no país), há apenas uma livraria de pequeno porte focada em best-sellers e livros infantis e religiosos.

Mais recentemente, a quarta edição da pesquisa Retratos da Leitura no Brasil, realizada pelo Ibope (Instituto Brasileiro de Opinião e Estatística), encomendada pelo Instituto Pró-Livro e divulgada em maio de 2016, apontou que o número de leitores no Brasil aumentou 6\% entre os anos de 2011 e 2015. O total de livros lidos pelos brasileiros nos últimos três meses anteriores a pesquisa foi de 2,54 obras. No entanto, o perfil das obras recordistas de leitura mudou substancialmente, de acordo com o levantamento. A Bíblia está em primeiro lugar entre os mais citados, o segundo lugar ficou com o livro intitulado "Diário de um banana", seguido do livro da youtuber Kéfera que empatou com o renomado autor da literatura brasileira, Machado de Assis. Ao todo, a pesquisa ouviu 5.012 pessoas em todos os estados do Brasil.

Mas se o cenário não é dos mais animadores, algumas instituições se propõem a incentivar e preservar a literatura na cidade, entre elas está a Academia Imperatrizense de Letras (AIL), fundada em 27 de abril de 1991. O caderno é publicado aos domingos e desde sua criação nunca passou por mudanças visuais ou editorais. Em 2011, a estudante de jornalismo da Universidade Federal do Maranhão (UFMA), Janaina Lopes de Amorim, 
apresentou uma proposta de reformulação do caderno. Porém, o novo modelo propunha um conteúdo voltado à editoria de Cultura, e não apenas para literatura, por isso não foi adotado pela instituição.

Diante desse cenário, este artigo busca resgatar e registrar a história do único suplemento de literatura da mídia impressa sul maranhense e, ainda, pensar numa possível reestruturação das páginas. Para coleta de dados e informações a respeito do Caderno Literário foram realizadas entrevistas abertas com o editor da página, o escritor Livaldo Fregona; e com o editor-chefe Sergio Godinho, responsável pelo Jornal O Progresso, no qual o caderno é veiculado. A presidente da Academia Imperatrizense de Letras, Edna Ventura, foi consultada por meio da realização de briefing $^{5}$, que guiou a proposta de formulação material do projeto.

\section{OS FOLHETINS E OS CADERNOS LITERÁRIOS}

Os folhetins representaram um importante espaço da literatura nos jornais, não só na cobertura do tema como também na experimentação escrita. Eles surgiram na França e, inicialmente, ocupavam apenas um "espaço de fim de página, que abrigavam um autêntico balaio de gatos textual de amenidades: curiosidades, casos extravagantes, charadas, anedotas, receitas culinárias etc. E uma parcela de ficção narrativa.” (BULHÕES, 2007, p. 33).

Logo depois, passou a inserir narrativas, o que foi chamado de romance-folhetim. Aos poucos a ficção se tornou um grande atrativo nos jornais, e o romance-folhetim ganhou mais espaço, consolidando-se na divulgação do romance Os mistérios de Paris, de Eugéne Sue.

Após esse romance, muitos desses passaram a publicar narrativas em jornais, entre eles grandes clássicos da literatura como $O$ conde de Monte Cristo, de Alexandre Duma, lançado no Journal des Débats; e A herança misteriosa, de Ponsondu Terrail, publicado no jornal La Patrie. De acordo com Bulhões (2007, p. 32), a fórmula do sucesso do folhetim era “a suspensão da narrativa no momento do clímax". No Brasil essas publicações se consagraram com o lançamento de obras importantes como Iracema de José de Alencar, e Dom Casmurro, de Machado Assis.

Porém, na década de 1950, os folhetins foram perdendo o seu espaço nos jornais impressos. A imprensa francesa deixou de ter influência na rotina brasileira, que foi buscar

\footnotetext{
${ }^{5}$ São informações preliminares contendo todas as instruções que o cliente fornece. "É baseado nele e completado com as informações de pesquisas que se esboça o planejamento" (S'ANTANNA, 1989, p. 109). In: DUARTE, Jorge (Org). Assessoria de Imprensa e Relacionamento com a mídia. 3. ed. São Paulo: Atlas, 2010.
}

Comun. \& Inf., Goiânia, GO, v. 20, n. 3, p. 49-63, out./dez. 2017 
inspiração nas normatizações norte-americanas, com a inclusão do lead e manuais de redação. Com a extinção dos folhetins, surgiram os cadernos literários. Grandes jornais da época, como Estado de São Paulo e Jornal do Brasil passaram a publicar suplementos deste tema na tentativa de preservar a literatura nos jornais e no meio social. O público principal era composto por intelectuais e acadêmicos.

Mas com jornais cada vez mais informativos, os cadernos literários também perderam o seu espaço por volta da década de 1970 . Hoje, eles estão cada vez mais raros e menores, considerados um artigo de luxo para os jornais impressos. Alguns ainda os mantêm publicados como O Sabático, do Estadão; e o Extra, do Jornal O Progresso, que, apesar das peculiaridades, ainda é o único a publicar um caderno literário no Maranhão.

\section{OS CADERNOS LITERÁRIOS}

Depois de adotarem uma linguagem mais objetiva, os jornais criaram espaços específicos para a literatura, deixando para trás os tempos em que a produção da imprensa e dos escritores eram confundidas. Assim, os suplementos literários da imprensa brasileira surgiram na década de 1950 para dar vazão a essa mudança. De acordo com Travancas (2001, p. 21), “[...] aos poucos a literatura vai diminuindo seu espaço e sua importância nos jornais [...] ficando restrita aos suplementos literários publicados pelos grandes jornais nos anos [1950]".

Essa foi considerada a época dourada dos cadernos literários na grande imprensa no Brasil, de acordo com Lorenzotti (2007), já que na década de 1950 foram lançadas as primeiras publicações nesse novo formato. Inicialmente, os cadernos literários abrangiam mais que a literatura, envolviam também temas relacionados à arte e à cultura, segundo a autora. Por isso, alguns meios de comunicação foram considerados os pioneiros, mesmo não adotando publicações exclusivamente literárias.

Sobre os primórdios dos temas culturais, alguns consideram que já constavam do Correio Brasiliense, ou Armazém Literário, nosso primeiro periódico, embora editado na Inglaterra. Correio Mercantil, 1843, Atualidade. Diário do Rio de Janeiro 1821, por exemplo, eram jornais informativos com seções de críticas literárias. (LORENZOTTI, 2007, p. 1314).

Com a informatização das redações na década de 1980, o espaço por textos longos e densos, que marcavam a era dos suplementos, começa a perder leitores. "As vertiginosas 
transformações nas áreas técnicas e de produção da imprensa, não davam mais lugar a um tipo de experiência que se pretendia mais artística que jornalística." (LORENZOTTI, 2007, p. 76).

$\mathrm{Na}$ atualidade, boa parte das coberturas sobre o tema literatura, na grande imprensa, ou se perde nos conteúdos noticiosos do dia a dia, ou precisa disputar espaço entre as pautas a serem levantadas como assuntos especiais nas publicações de fim de semana.

\section{JORNAL O PROGRESSO}

Fundado em 3 de maio de 1970, O Progresso é o mais antigo jornal em circulação na cidade de Imperatriz, a segunda maior do Maranhão. O tipógrafo e empresário José Matos Vieira e o advogado e jornalista Jurivê de Macedo idealizaram e fundaram o jornal. De acordo com o atual diretor de $O$ Progresso, Sergio Henrique Godinho, o jornal foi fundado porque "viu-se a necessidade de criar um órgão de imprensa, já que não tinha na região" (informação verbal $)^{6}$. O primeiro chefe de redação foi o jornalista Helius de Monção e o primeiro repórter foi Otávio Barros. Inicialmente, o jornal tinha publicação semanal e possuía quatro páginas. Depois de algumas edições, passou-se a investir nos equipamentos.

Meses depois, passou a circular duas vezes por semana e a funcionar em prédio próprio. Foram contratados novos jornalistas, além de colunistas de outras cidades. Em 1975, o jornal foi comprado pelo promotor de justiça Sergio Antônio Nahuz Godinho. A nova administração tornou o jornal diário e o aumentou de quatro para doze páginas. Mas, de acordo com Adalberto Franklin (2010), era difícil mantê-lo e, por isso, depois de dois anos o jornal foi novamente vendido. "As enormes dificuldades na manutenção e administração de um jornal diário, numa cidade do interior do Estado, apresentam-se imediatamente, desestimulando o novo proprietário"7.

Durante meses $O$ Progresso deixou de circular. Até que, em 1978, o antigo dono, Sergio Godinho, tornou a comprar o jornal. "Sergio Godinho retorna para Imperatriz e decide retomar o desafio de manter o jornal. Mesmo sacrificando sua banca de advocacia e uma imobiliária de sua propriedade, investe e recupera $O$ Progresso. Sua disposição é colocar o jornal a serviço da comunidade" (FRANKLIN, 2010). Em 1986, o historiador Adalberto Franklin passa a dirigir o jornal. Nessa época, as publicações continham dezesseis páginas, sendo que, aos domingos, apresentava vinte páginas, quando eram adicionados dois cadernos.

\footnotetext{
${ }^{6}$ Entrevista concedida por Sérgio Godinho, diretor geral do Jornal O Progresso, no dia $01^{\circ}$ nov. 2012 às $17 \mathrm{~h}$.

7 Disponível em: http://oprogressonet.com.
} 
Hoje o jornal acumula mais de 40 anos de publicações e abrange, além de Imperatriz, cidades do Sul do estado, a capital São Luís e parte do estado do Tocantins. O jornal é composto por dezesseis páginas, contendo sete editorias: Política, Regional, Cidade, Polícia, Esporte, Tocantins e Justiça. Aos domingos publica dois cadernos: Extra, de conteúdo literário, composto por três páginas, que é de responsabilidade da Academia Imperatrizense de Letras (AIL); e o Caderno de Domingo, que contém resumos de novelas e notícias sobre celebridades. Atualmente, a tiragem é de 3.500 jornais por dia, enquanto aos domingos chega a 4.500. Em novembro de 2012, O Progresso publicou pela primeira vez a capa do jornal colorida.

\section{CADERNO DE LITERATURA DA ACADEMIA IMPERATRIZENSE DE LETRAS}

A Academia Imperatrizense de Letras (AIL) foi fundada no dia 27 de abril de 1991. $\mathrm{Na}$ atualidade, a instituição tem 40 membros interinos, com cadeiras ocupadas por escritores de Imperatriz. Cerca de dez anos após a fundação da AIL, o também fundador da instituição, Edmilson Sanches, criou o caderno literário composto pelas páginas: Extra, Espaço dos Estudantes e Espaço das Letras. Como jornalista, Edmilson Sanches criou o espaço para divulgação e preservação da literatura na Região Tocantina. Em parceria com o jornal $O$ Progresso, a Academia Imperatrizense passou a publicar o suplemento todos os domingos.

De acordo com Sergio Godinho, esse era um produto de interesse do jornal por não haver conteúdo desse formato sendo publicado em todo o Estado: "A população que lia o jornal em Imperatriz e região precisava ter um jornal não só de notícias populistas, mas também que fortalecesse o intelectual. É uma maneira de dar espaço para escritores publicarem seus textos." (informação verbal) ${ }^{8}$.

Hoje, o suplemento é uma das principais formas de divulgação da produção literária e das ações da instituição, segundo a presidente Edna Ventura. "O caderno é de grande importância, pois é o único espaço literário que temos para divulgar a produção literária da região e divulgar mais as ações da Academia de Letras, as obras dos acadêmicos." (informação verbal) ${ }^{9}$.

O modelo do caderno literário foi determinado pelo próprio jornal O Progresso. "Foi pensada e formatada pelo jornal, e entregue à Academia um documento base com títulos,

\footnotetext{
${ }^{8}$ Entrevista concedida por Sérgio Godinho, diretor geral do Jornal O Progresso, no dia $01^{\circ}$ nov. 2012 às $17 \mathrm{~h}$.

${ }^{9}$ Entrevista concedida por Edna Ventura presidente da AIL, no dia 08 nov. 2012 às 15 h.
}

Comun. \& Inf., Goiânia, GO, v. 20, n. 3, p. 49-63, out./dez. 2017 
layout e etc." (informação verbal) ${ }^{10}$. A primeira página desse formato inclui um perfil de um escritor de destaque em Imperatriz, juntamente com a publicação de suas obras.

A página voltada para a AIL, Espaço das Letras, possui uma coluna chamada Notícias da Academia com informações e comunicados relacionados à instituição. Por fim, a coluna Hoje é domingo de..., cujas edições apresentam a publicação de uma obra de um dos confrades $^{11}$.

Metade da segunda página do caderno, intitulada Espaço dos Estudantes, é reservada para a publicação de obras de alunos de níveis variados, do Ensino Fundamental ao Superior, contendo nome completo do autor e a escola à qual pertence. De acordo com a presidente da entidade, Edna Ventura, a AIL incentivava escolas com as quais tinham contato para encaminhar trabalhos literários produzidos por seus alunos. Os textos enviados pelos estudantes eram analisados e, se considerados adequados, eram publicados na página. As demais páginas são alimentadas com colunas de colaboradores do jornal.

Em 2007, quando o membro da academia, Livaldo Fregona, assumiu a edição do caderno, não houve qualquer mudança editorial. De acordo com o atual editor, desde que assumiu a edição, segue apenas os padrões determinados: "Eles [o jornal] me entregaram a página em um formato, apenas para eu preencher" (informação verbal) ${ }^{12}$. Em entrevista, Fregona explicou que não há critério de seleção de conteúdo e que os interessados na publicação é que o procuram:

No começo eu saía de porta em porta, pedindo conteúdo para publicar na página Extra, no Espaço da Letras, na Página dos Estudantes. Hoje eu coloco as matérias em fila de espera. Por exemplo, se um alguém escreve sobre finados, e está na semana de novembro eu vou dar preferência àquela, vou escolhendo de acordo com o que estão falando mais naquele momento. Ou escolho aquele que está há muito tempo sem sair. (informação verbal) ${ }^{13}$.

O caderno literário também é isento de qualquer forma de publicidade. Uma escolha feita pelo próprio jornal, que afirma não ver o suplemento como um produto lucrativo, embora o editor do veículo discorde.

\footnotetext{
${ }^{10}$ Entrevista concedida por Sérgio Godinho, diretor geral do Jornal O Progresso, no dia $01^{\circ}$ nov. 2012 às $17 \mathrm{~h}$.

${ }^{11}$ São chamados de confrades aqueles que são membros da Academia Imperatrizense de Letras.

${ }^{12}$ Entrevista com Livaldo Fregona, editor do caderno Extra, concedida para esta pesquisa, no dia $01^{\circ}$ nov. 2012 às $17 \mathrm{~h}$

${ }^{13}$ Entrevista com Livaldo Fregona, editor do caderno Extra, concedida para esta pesquisa, no dia $01^{\circ}$ nov. 2012 às $17 \mathrm{~h}$.
}

Comun. \& Inf., Goiânia, GO, v. 20, n. 3, p. 49-63, out./dez. 2017 
Acredito que seja lucrativo do ponto de vista da importância que damos ao Caderno Literário e não em termos lucrativos para nós. Porque em nenhum momento fizemos esta parceria com a Academia de colocar este produto dentro do jornal com o objetivo de vender anúncios. (informação verbal) ${ }^{14}$.

Mesmo isento de propaganda, o diretor revela que o produto se tornou rentável de outra forma e também afirma estar satisfeito com a participação, alcance e venda do caderno literário. "A Academia, que produz este material, tem feito um produto de qualidade. Com isso estamos satisfeitos. A venda cresceu no domingo porque é um jornal mais completo, que desperta curiosidade no leitor." (informação verbal) ${ }^{15}$.

O jornal $O$ Progresso tem uma tiragem de 3 mil exemplares por dia, porém aos domingos, dia em que o caderno é publicado, há um aumento de mil exemplares.

\section{REFORMULAÇÃO}

A instituição e o jornal acreditam que, ao longo dos anos, o caderno literário contribuiu para a difusão da cultura local por meio da Literatura e, apesar de seguir um modelo padrão, ambos concordaram ao afirmar que é necessária uma reformulação para tornar essa propagação mais efetiva.

Mudanças sempre são bem-vindas, principalmente se for com a finalidade de melhorar. Sou a favor de mudanças estruturadas que venham trazer resultados significativos. $O$ Progresso não está fechado a sugestões e a novos projetos. (informação verbal) ${ }^{16}$.

A presidente da AIL e o atual editor das páginas também acham interessante a ideia de modernizar o caderno literário e propor novos conteúdos que divulguem ainda mais a produção literária dos membros da Academia e dos escritores que utilizam esse espaço para publicar obras locais. Nesse sentido, esse artigo tentou aplicar os conceitos que abarcam as discussões teóricas sobre o papel e formato do que se entende por jornalismo de cobertura literária e buscou um resultado prático para esse estudo, apresentando, como parte da pesquisa, uma possível mudança para o caderno, embora seja uma tese do que seria mais viável para o suplemento não sendo, efetivamente, uma proposta comercial.

\footnotetext{
${ }^{14}$ Entrevista concedida por Sérgio Godinho, diretor geral do Jornal O Progresso, no dia $01^{\circ}$ nov. 2012 às $17 \mathrm{~h}$.

${ }^{15}$ Entrevista concedida por Sérgio Godinho, diretor geral do Jornal O Progresso, no dia 01 ${ }^{\circ}$ nov. 2012 às $17 \mathrm{~h}$.

${ }^{16}$ Entrevista concedida por Sérgio Godinho, diretor geral do Jornal O Progresso, no dia 01 ${ }^{\circ}$ nov. 2012 às $17 \mathrm{~h}$.
}

Comun. \& Inf., Goiânia, GO, v. 20, n. 3, p. 49-63, out./dez. 2017 
O novo produto foi publicado por três domingos seguidos no mês de junho, nos dias: 9,16 e 23 . Vale ressaltar que essa foi a primeira vez que o caderno foi produzido e publicado com enfoque jornalístico e sob orientação de editoras com conhecimento da área.

Antes da reformulação, o encarte era composto por três páginas. A primeira vinha com o perfil de personalidades, seguido de um espaço destinado a sua obra. Na segunda página, metade do espaço era destinado a publicações de obras de estudantes e o restante era ocupado por uma coluna semanal que publicava textos sobre diversos assuntos. A terceira página, que recebe o título Espaço das Letras, havia uma coluna com notícias da Academia e meia página para o perfil de membros da instituição e a publicação de sua obra. A quarta e última página também era alimentada por colunistas. Todo o material era produzido pelos escritores que fazem parte da Academia Imperatrizense de Letras e editado pelo membro Livaldo Fregona e os colaboradores do Progresso, não por jornalistas. A reformulação mostra que o olhar jornalístico é necessário para a produção desse tipo de conteúdo, porque além de ser uma fonte de entretenimento, também objetiva a informação.

A diagramação do antigo caderno não seguia padrão de tamanho, fonte ou espaço das entrelinhas, e a parte gráfica era elaborada de acordo com a quantidade de conteúdo. O novo produto, além de estabelecer padrões de diagramação, determinou novas sessões e produção de conteúdo.

Para a elaboração de conteúdo do caderno foi levado em conta o seguinte critério de seleção: pautas exclusivamente do mundo literário da Região Tocantina. Considerando o fato do caderno literário da AIL ser a única publicação específica de literatura na mídia impressa do Maranhão, a proposta de reformulação também buscou oferecer coberturas mais completas sobre o tema ao incluir notícias, reportagens e entrevistas.

Figura 1 - Breve comparação de como ficou suplemento literário de $O$ Progresso antes e depois
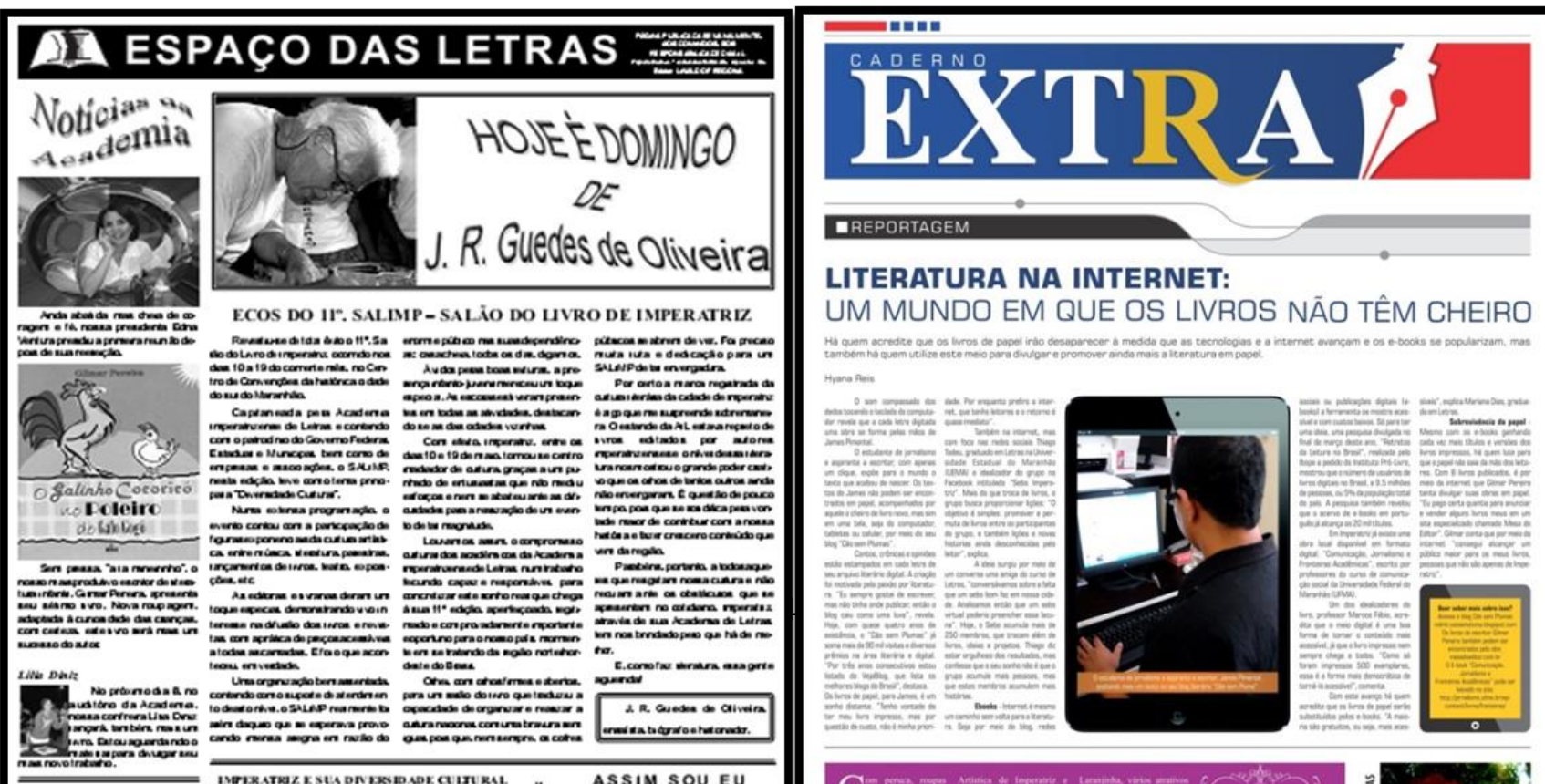
$\mathrm{Na}$ segunda página, buscou-se fornecer um espaço de entretenimento e informação. Portanto, foi criada a sessão Na Estante, destinada a resenhas de livros. Logo abaixo, fica a sessão Calendário Literário, que contém uma agenda com eventos, palestras, lançamentos e acontecimentos relacionados à literatura e à cultura. A finalidade é divulgar a produção dos escritores imperatrizenses como um produto a ser consumido, pois os autores locais necessitam de um espaço para anunciar suas obras. Somente os membros da Academia de Letras possuem, juntos, mais de 300 obras publicadas e nenhum espaço específico para sua divulgação. E em cadernos de cunho cultural como a página Extra, gêneros opinativos, como as resenhas, e a agenda exercem um importante papel no quesito divulgação, por serem meios de indicar e orientar o leitor sobre qual o melhor produto de entretenimento, sob o ponto de vista de um profissional que entende do assunto.

Por fim, a segunda página possui uma charge humorística relacionada à literatura que busca despertar para um assunto ou problemática de maneira irônica. Por determinação de $O$ Progresso, a página manteve-se com o nome Espaço dos Estudantes.

A página 3 na antiga edição do caderno Extra era intitulada Espaço das Letras, porque era voltada exclusivamente para os membros da AIL. E para contemplar os membros da AIL nessa página, como destaque, há uma entrevista com os confrades relacionados à área de atuação, como por exemplo: literatura infantil e pedagogia da literatura. Suas obras também ganham espaço nessa página. Ao lado da entrevista foi criado uma sessão com a publicação de um texto de sua autoria intitulado Obras do Escritor. Por fim, foi mantida a coluna Notícias da Academia, oriunda do antigo caderno, cujo objetivo é informar sobre as ações da 
Academia de Letras.

Para a reformulação foi utilizada uma linguagem típica dos cadernos de literatura, com base na definição de Travancas (2001, p. 55) que diz que: “os textos podem ser mais extensos, podem ser mais complexos e a linguagem mais refinada e menos coloquial".

Apesar de manter o gênero informativo como foco, buscou-se dinamizar os textos, utilizando-os de maneira criativa, pois a editoria de literatura deve ser tratada de forma diferenciada, por não se tratar de conteúdo meramente factual, mas de entretenimento. Por isso, muitas edições receberam títulos de cunho fantasioso, e o texto típico da notícia deu espaço para descrições e narrativas mais detalhadas.

O caderno foi diagramado nas medidas do antigo suplemento, baseado no estabelecido pelo jornal O Progresso: Tamanho standard de $313 \mathrm{~mm} \times 451 \mathrm{~mm}$, com margem interna e externa de $9 \mathrm{~mm}$, e superior e inferior de $3 \mathrm{~mm}$, com textos distribuídos em quatro colunas. $\mathrm{O}$ antigo suplemento, desde sua criação, era publicado em preto e branco com algumas variações de azul e vermelho. A direção do jornal O Progresso permitiu que o novo produto fosse publicado com a primeira e a última página coloridas. Devido a essa mudança, foi necessário alterar a paginação. O caderno era composto por quatro páginas, sendo a primeira, a terceira e metade da segunda da instituição; os demais espaços eram ocupados por colunas de escritores parceiros do jornal. Com o novo produto colorido, a terceira página foi descolada e se tornou a página 4 , assim, as colunas foram descoladas para a parte central do caderno.

Uma das mudanças propostas pelo novo caderno foi em relação à logomarca. Antigamente, na retranca, era utilizado somente o nome "Extra" com uma fonte na cor azul.

Para respeitar os padrões de cores de O Progresso e ao mesmo tempo oferecer uma nova identidade visual ao caderno, foi criado um logotipo nas cores do jornal: azul, vermelho e amarelo. Optou-se por uma pena por ser instrumento utilizado antigamente para escrever, um meio de representar os escritores e a literatura.

\section{CONSIDERAÇÕES FINAIS}

Por muito tempo a definição de jornalismo literário ficou atrelada à produção jornalística em formato de livro-reportagem. No entanto, percebe-se que a amplitude do conceito não permite que o mesmo seja resumido de forma simplista. A definição de jornalismo literário rompe com o tradicional modelo do lead que responde às perguntas 
elementares: Quem? O que? Como? Onde? Quando? Por quê? No entanto, é preciso entender que:

\begin{abstract}
O jornalista literário não ignora o que aprendeu no jornalismo diário. Nem joga suas técnicas narrativas no lixo. O que ele faz é desenvolvê-las de tal maneira que acaba constituindo novas estratégias profissionais. Mas os velhos e bons princípios da redação continuam extremamente importantes, como, por exemplo, a apuração rigorosa, a observação atenta, a abordagem ética e a capacidade de se expressar claramente, entre outras coisas. (PENA, 2006, p. 7)
\end{abstract}

Isso ficou claro em nosso estudo que demonstrou também o quanto a pesquisa aplicada pode render bons frutos à comunicação. Isso porque, dessa forma, podemos compreender a evolução do jornalismo literário em um jornal impresso que abarca uma população importante do país, conhecida como região Tocantina. Ficou evidente também que o jornalista pode aplicar ideias inovadoras, buscando deixar o produto mais atrativo, sem fugir dos princípios fundamentais do jornalismo.

Outra constatação importante é que um caderno literário ainda é um produto que gera leitura, apesar de muitos pensarem de forma contrária. Um aspecto positivo que também deve ser levado em consideração em um momento de comunicação instantânea é que o caderno literário rompe com características elementares do jornalismo, como a periodicidade e a atualidade, dessa forma, o produto pode ser consumido independente do dia de sua publicação, além de permitir uma abrangência de fontes, fugindo daquela proposta pelo jornalismo tradicional.

O Caderno Extra é o único suplemento literário em publicação atualmente na região, portanto um importante meio utilizado pela Academia Imperatrizense de Letras para cumprir sua missão enquanto instituição: a divulgação e preservação da literatura. Por meio da reformulação é possível melhor abordar as pautas de literatura de Imperatriz e promover novos espaços para escritores e amantes desta arte.

\title{
REFERÊNCIAS
}

ASSOCIAÇÄO Nacional de Jornais - ANJ (2012). Disponível em: <http://www.anj.org.br〉. Acesso em: 19 ago. 2012.

BULHÕES, Marcelo. Jornalismo e Literatura em convergência. São Paulo: Ática, 2007. DINES, Alberto. O papel do jornal: uma releitura. São Paulo: Summus, 1986. 
FRANKLIN, Adalberto. Memória. 2010. Disponível em: <oprogressonet.com>. Acesso em: 18 ago. 2012.

LAGE, Nilson. Questão de estilo: Evolução dos Manuais de Redação no Brasil. Estudo de caso dos Manuais de Redação dos jornais Folha de São Paulo e O Estado de São Paulo, 1999. Disponível em: http://www.intercom.org.br/papers/regionais/sudeste2008/resumos/R9-02181.pdf. Acesso em: 18 set. 2012.

LORENZOTTI, Elizabeth. Suplemento Literário que falta ele faz. São Paulo: Imprensa Oficial do Estado de São Paulo. 2007.

PENA, Felipe. O jornalismo Literário como gênero e conceito. Trabalho apresentado no Encontro dos Núcleos de Pesquisa da Intercom. 2006.

RETRATOS da Leitura no Brasil. Disponível em: http://www.portalct.com.br/vivertocantins/2012/04/25/43214-com-baixos-indices-de-leitura-estados-da-amazonia-legal-entreeles-o-to-terao-atencao-especial-em-pr. Acesso em: 05 jan. 2013.

RETRATOS da Leitura no Brasil. Disponível em: http://prolivro.org.br/home/images/relatorios_boletins/3_ed_pesquisa_retratos_leitura_IPL.pd f. Acesso em: 22 maio 2016.

TRAVANCAS, Isabel. O livro no Jornal: os suplementos literários dos jornais franceses e brasileiros nos anos 90. São Paulo: Ateliê Editora, 2001. 